\title{
Plant Expression of Hydrophobin Fused K39 Antigen for Visceral Leishmaniasis Immunodiagnosis
}

\section{OPEN ACCESS}

Edited by:

Marcello Donini,

Italian National Agency for New

Technologies, Energy and Sustainable Economic Development

(ENEA), Italy

Reviewed by:

Linda Avesani,

University of Verona, Italy

Chiara Lico,

Italian National Agency for New

Technologies, Energy and Sustainable Economic Development

(ENEA), Italy

*Correspondence:

Maria Izabel F. Guedes

izabel.guedes@uece.br

tThese authors have contributed equally to this work and share first authorship

Specialty section: This article was submitted to Plant Biotechnology, a section of the journal Frontiers in Plant Science

Received: 28 February 2021 Accepted: 29 April 2021 Published: 31 May 2021

Citation:

Silva BB, Santos ENFN, Araújo LS, Bezerra AS, Marques LÉC, Tramontina Florean EOP, van Tilburg MF and Guedes MIF (2021) Plant Expression of Hydrophobin Fused K39 Antigen for Visceral Leishmaniasis Immunodiagnosis.

Front. Plant Sci. 12:674015. doi: 10.3389/fp/s.2021.674015

\author{
Bruno B. Silva ${ }^{1,2 t}$, Eduarda N. F. N. Santos ${ }^{1,2 t}$, Lucelina S. Araújo ${ }^{1}$, Arnaldo S. Bezerra ${ }^{1,2}$, \\ Lívia É. C. Marques ${ }^{1}$, Eridan O. P. Tramontina Florean ${ }^{3}$, Maurício F. van Tilburg ${ }^{2,4}$ and \\ Maria Izabel F. Guedes ${ }^{1,2^{*}}$
}

'Laboratory of Biotechnology and Molecular Biology, Health Sciences Center, State University of Ceará, Fortaleza, Brazil, ${ }^{2}$ Northeast Biotechnology Network (RENORBIO), State University of Ceará, Fortaleza, Brazil, ${ }^{3}$ Department of Biochemistry and Molecular Biology, Federal University of Ceará, Fortaleza, Brazil, ${ }^{4}$ Department of Animal Sciences, Federal Rural University of the Semiarid, Mossoró, Brazil

Visceral leishmaniasis is a Neglected Tropical Disease of high mortality caused by the protozoan Leishmania infantum. Its transmission cycle is complex, and it has in the domestic dog its main reservoir. The diagnostic tests currently used rely on prokaryotic systems' proteins, but their low sensitivity increases the disease's burden. The plant transient expression of recombinant proteins allows the production of complex antigens. However, this system has limited competitiveness against the bacterial production of purified antigens. Thus, we have shown that the L. infantum K39 antigen's fusion to a hydrophobin allows its production for diagnostic tests without the need for intensive purification. The sera of naturally infected dogs specifically detect the semi-purified rK39HFBI protein. The test validation against a panel of 158 clinical samples demonstrates the platform's viability, resulting in sensitivity and specificity of 90.7 and $97.5 \%$, respectively. Thus, the use of semi-purified antigens fused to hydrophobins can become the standard platform for large-scale antigens production to expand diagnostic tests for other human and veterinary diseases worldwide.

Keywords: visceral leishmaniasis, plant transient expression, recombinant proteins, hydrophobins, neglected tropical diseases, immunodiagnosis

\section{INTRODUCTION}

Visceral leishmaniasis is a Neglected Tropical Disease that annually afflicts 300,000 people worldwide, resulting in the death of 20,000 of them (World Health Organization, 2018; Ruiz-Postigo et al., 2020). In the Americas, visceral leishmaniasis is a zoonotic disease, with the transmission cycle involving the domestic dog (reservoir), the protozoan Leishmania infantum (etiological agent) and the sandfly Lutzomyia longipalpis (primary vector; Burza et al., 2018). Brazil accounts for $96 \%$ of all visceral leishmaniasis cases reported in Latin America (WHO-PAHO, 2018), highlighting the need for new strategies of prophylaxis, diagnosis and treatment for the control of the disease.

The Brazilian government's main prophylactic measures are the serological surveys followed by the culling of infected dogs (Marcondes and Day, 2019). The epidemiological surveillance 
is performed in two steps: an immunochromatographic screening test (DPP ${ }^{\circledR}$ Dual Path Platform Biomanguinhos/Fiocruz, Brazil) followed by a confirmatory immunoenzymatic assay (ELISA $^{\circledR}$ kit EIE-LVC Bio-Manguinhos/Fiocruz, Brazil; de Carvalho et al., 2018; Teixeira et al., 2019).

The serological diagnosis of visceral leishmaniasis relies on the recombinant K39 antigen expressed in Escherichia coli (Faria and de Andrade, 2012). The K39 protein is predominant in the amastigote stage of $L$. infantum, and it belongs to the kinesin superfamily. These proteins comprise a class of eukaryotic motor proteins involved in microtubule-based movements. The tandem repeats of the kinesins are responsible for proteinprotein interaction and its oligomerization inside the cell (Verhey et al., 2011). Tandem repeats proteins from many parasitic protozoans have immunodominant epitopes for antibody production. The number of antibodies that bind to these antigens is proportional to their number of repeats (Goto et al., 2010).

Low-cost diagnostic tests could be developed using less purified heterologous proteins from plants (Buyel, 2019; Marques et al., 2020), an approach that would not be feasible with products from bacterial systems due to the higher antigenicity of the host proteins, demanding their removal by multiple chromatographic steps and increasing the costs for the development of immunodiagnostic tests (Robichon et al., 2011; Tripathi, 2016). The fusion of a plant produced antigen to a hydrophobin partner from Trichoderma reesei allows its accumulation at high levels in the plant cell and its subsequent purification by a non-chromatographic and straightforward Aqueous Two-Phase System (ATPS; Linder et al., 2004; Saberianfar and Menassa, 2017).

Thus, the present work describes the plant transient expression of the hydrophobin fused rK39 antigen from L. infantum. Upon ATPS, we demonstrated that the construct was partitioned to an rK39-HFBI semi-purified extract. Compared to the purified rK39 produced in E. coli, the rK39-HFBI semi-purified extract showed an equivalent performance, which highlights its suitability as a platform for the development of immunodiagnostic tests for canine visceral leishmaniasis.

\section{MATERIALS AND METHODS}

\section{Media}

YM medium composition was $0.04 \%$ Yeast extract, $1.0 \%$ Mannitol, $\quad 1.7 \mathrm{mM} \mathrm{NaCl}, \quad 0.8 \mathrm{mM} \quad \mathrm{MgSO} 4$, and $2.2 \mathrm{mM} \mathrm{K} 2 \mathrm{HPO}$. Infiltration media was prepared by the supplementation of YM medium with MES buffer ( $\mathrm{pH}$ 5.6; Sigma, M3671) and acetosyringone (Sigma, D134406) to a final concentration of $10 \mathrm{mM}$ and $100 \mu \mathrm{M}$, respectively. Gamborg's solution composition was $10 \mathrm{mM}$ MES, $200 \mu \mathrm{M}$ acetosyringone, $20 \mathrm{~g} / \mathrm{L}$ sucrose and $3.2 \mathrm{~g} / \mathrm{L}$ of Gamborg's B-5 Basal Medium (Sigma, G5893; Kapila et al., 1997).

\section{Construct Synthesis and Cloning}

The L. infantum K39 gene (Accession Number: DQ831678.1) was optimized for expression in Nicotiana benthamiana and synthesized by BioBasic Inc. (Ontario, Canada). The synthesized construct was flanked by the AttL1 and AttL2 sites to be promptly cloned into the pCAMGate-ER-HFBI expression vector using the Gateway LR Clonase Enzyme Mix II (Invitrogen, 11791020).

This pCAMGate-ER-HFBI plasmid is part of the pCaMGate plant binary expression series. Upstream to its cloning site, the expression cassette encompasses a double enhanced cauliflower mosaic virus $35 \mathrm{~S}$ promoter, the tCUP translation enhancer, the Pr1b secretory signal peptide from tobacco and the Xpress tag for construct detection. After recombination, the 3' end of the subcloned K39 gene is fused by a 3(GSSS) linker to the HFBI gene. Once expressed, the construct also displays a human c-myc detection/purification tag and a KDEL retention signal at its c-terminus (Pereira et al., 2014).

The recombination product was transformed into chemically competent E. coli DH10B, and a positive clone was selected by colony PCR using vector-specific primers for the $35 \mathrm{~S}$ promoter (P-35S: CCTTCGCAAGACCCTTCCTCTAT) and nos terminator sequences (T-nos: CCGGCAACAGGATTCAATCTTAA). The pCAMGATE-ER-rK39-HFBI plasmid was transformed into chemically competent Agrobacterium tumefaciens LBA4404 (Invitrogen, 18313015) plated into YM medium with the antibiotics kanamycin $(50 \mu \mathrm{g} / \mathrm{ml})$ and streptomycin $(100 \mu \mathrm{g} /$ $\mathrm{ml}$ ). The same plant expression vector harboring a Green Fluorescent Protein (GFP) was used as a control for the experiments (Figures 1A,B).

\section{Production of rK39 in E. coli}

The same K39 coding sequence was cloned into the plasmid pET-28a (Novagen, Darmstadt, Germany) using classical molecular cloning techniques (Figure 1C). The recombinant plasmid obtained was confirmed by capillary sequencing (Helixxa Genomic Services) and then transformed into E. coli BL21-DE3 (Invitrogen, C600003).

For the expression of rK39, a pre-inoculum was diluted (1:25) in LB-kanamycin and incubated at $37^{\circ} \mathrm{C}$ under agitation $(250 \mathrm{rpm})$. When the optical density (OD600 $\mathrm{nm}$ ) reached $0.6-0.8$, the induction process was initiated, using the inducing agent Isopropyl $\beta$-D-1-thiogalactopyranoside (IPTG; Sigma, $10724815001)$ in three different concentrations $(0.1 ; 0.5$; and $1 \mathrm{mM})$. After $3 \mathrm{~h}$ of incubation, the bacteria were centrifuged at $8,000 \times g, 4^{\circ} \mathrm{C}$, for $15 \mathrm{~min}$ and the resulting pellet resuspended in lysis buffer [200 mM NaCl (Vetec); 20 mM Tris-HCl (USB/ Dynamic) $\mathrm{pH}$ 8.0; $200 \mu \mathrm{g}$ lysozyme; $2 \mathrm{mM}$ phenylmethanesulfonyl fluoride (PMSF; Sigma, P7626) with 1\% Triton X-100 (USB)]. The samples were sonicated (12 cycles of $15 \mathrm{~s})$ and then centrifuged $\left(8,000 \times g, 4^{\circ} \mathrm{C}, 15 \mathrm{~min}\right)$. The $\mathrm{rK} 39$ protein was purified by immobilized metal affinity chromatography from the supernatant of the bacterial extract. The samples were loaded into a Ni-NTA column (GE Healthcare, United States) previously equilibrated (20 mM Tris $\mathrm{pH} 8.0 ; 500 \mathrm{mM} \mathrm{NaCl}$; $10 \%$ glycerol; $20 \mathrm{mM}$ imidazole). After the washing step, the retained recombinant proteins were retrieved using an elution buffer (20 mM Tris pH 8.0; $500 \mathrm{mM} \mathrm{NaCl} ; 10 \%$ glycerol; $500 \mathrm{mM}$ imidazole; Rodrigues et al., 2005). The purified proteins were analyzed by SDS-polyacrylamide gel electrophoresis (SDSPAGE) and Western Blotting, using the monoclonal anti-His6 antibody (GE Healthcare Life Sciences) diluted 1:6,000. 
A

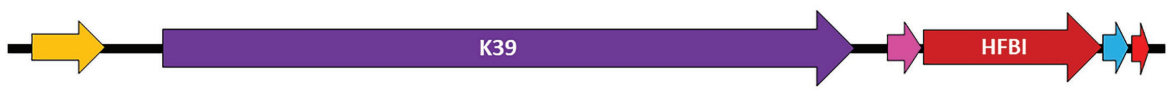

B

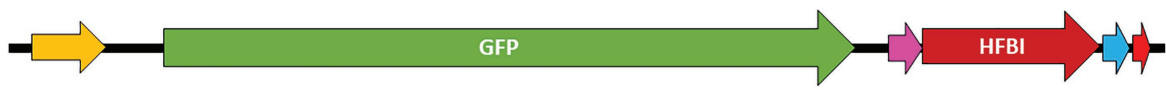

C

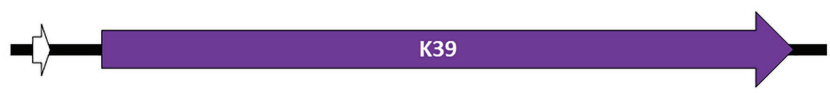

\begin{tabular}{|llll|}
$\square$ Pr1b & $\Rightarrow$ K39 & $\square$ GSSS Linker & $\square$ HFBI \\
$\square$ c-myc tag & $\Rightarrow$ KDEL & $\square$ GFP & $\square$ His $_{6}$ tag \\
\hline
\end{tabular}

FIGURE 1 | Schematic diagram of the constructs used. (A) Construct used for plant expression of the K39 protein from Leishmania infantum in the pCAMGateER-HFBI vector. (B) A construct containing the Green Fluorescent Protein (GFP) as a control for the plant expressed protein in the serological assays. (C) Construct used for Escherichia coli expression of the K39 protein in the pET-28a vector. Pr1b: tobacco pathogenesis-related protein 1b secretory signal peptide; K39: L. infantum's K39 coding sequence; GSSS: 3(GSSS) linker; HFBI: hydrophobin I gene from the fungus Trichoderma reesei; c-myc tag: human c-myc sequence for the detection of the recombinant protein; KDEL: endoplasmatic reticulum retention signal; GFP: Green Fluorescent Protein coding sequence; His 6 -tag: Six histidine residues for recombinant protein detection and purification by immobilized metal affinity chromatography.

\section{Mice Immunization for the Production of rK39 Antisera}

Six female mice $(\mathrm{BALB} / \mathrm{c})$, aged $6-8$ weeks and weighing 25-30 g, were obtained from the Nucleus of Experimental Biology (Nubex) of the University of Fortaleza (Unifor). The animals were kept under controlled temperature and humidity conditions, with a light-dark cycle of $12 \mathrm{~h}$. Throughout the experiment, feed and water were provided ad libitum.

After acclimatization, the animals were subcutaneously immunized with $20 \mu \mathrm{g}$ of the purified rK39 protein associated with Freund's complete adjuvant (Sigma-Aldrich), receiving boosters with Freund's incomplete adjuvant on the 21st and 35 th days after the beginning of the immunization. To obtain the antisera, the animals had their blood collected by the retro-orbital plexus on day 0 (pre-immune) and the 42 nd day after the start of immunization (Mello et al., 2011). The sera were stored at $-20^{\circ} \mathrm{C}$ until its use.

\section{Nicotiana benthamiana Agroinfiltration}

A single A. tumefaciens colony harboring the plasmid pCAMGATE-ER-rK39-HFBI or pCAMGATE-ER-GFP-HFBI was picked from fresh plates to prepare each inoculum. The same was done to an A. tumefaciens clone harboring the coding sequence to the p19 silencing inhibitor from Cymbidium ringspot virus (CymRSV). After overnight growth, both inocula were diluted $(1: 1,000)$ into infiltration media, and they were then incubated at $28^{\circ} \mathrm{C}(220 \mathrm{rpm})$ overnight. After reaching an OD600 of $0.8-1.0$, the cultures were centrifuged $(4,000 \times g$; $30 \mathrm{~min} ; 22^{\circ} \mathrm{C}$ ), and the resulting pellets were resuspended into MMA solution to an OD600 of 1.0. After 1-h incubation under gentle shaking at room temperature, the resuspended cells were mixed $(1: 1)$ for plant infiltration. The leaves of 6-8 weeks old $N$. benthamiana plants were infiltrated using a needleless syringe. Control plants were infiltrated only with the p19 culture (Pereira et al., 2014). The plants were kept at $25^{\circ} \mathrm{C}$ with a photoperiod of $16 \mathrm{~h}$ and on hydroponic solution along with the whole experiment.

\section{rK39-HFBI Extraction and ATPS Purification}

The infiltrated leaves were collected at 2, 4, 6, and 8days post infiltration (d.p.i.). On these days, leaves of three different plants were collected. A $4 \mathrm{~cm}^{2}$ piece of each leaf was weighted and then grounded on a microtube with three volumes of ice-cold extraction buffer [PBS with 0,1\% Triton $^{\mathrm{TM}} \mathrm{X}-100$ (Sigma, T8787) and $10 \mathrm{mM}$ PMSF (Sigma, P7626)]. The macerated leaves were centrifuged $\left(10,000 \times g ; 10 \mathrm{~min} ; 4^{\circ} \mathrm{C}\right)$, and the supernatant was stored at $-20^{\circ} \mathrm{C}$ for posterior analysis. All the experiments were performed on three independent batches of plants.

For ATPS purification, the agroinfiltrated leaves were harvested, weighted, and grounded on a mortar with liquid nitrogen. Six volumes of buffer were added to the powdered leaves that were then incubated for $1 \mathrm{~h}$ at $4^{\circ} \mathrm{C}$ under gentle shaking. The leaves were filtered on mousseline cloth and afterward centrifuged $\left(6,000 \times g ; 30 \mathrm{~min} ; 4^{\circ} \mathrm{C}\right)$. The supernatant was collected on new tubes, to which 2, 4, or $8 \%(\mathrm{v} / \mathrm{v})$ of Triton $^{\mathrm{TM}} \mathrm{X}-114$ (Sigma, $\mathrm{X} 114$ ) was added and homogenized by vortexing. The tubes were incubated in a heat block at $30^{\circ} \mathrm{C}$ until phase separation was stable (approximately $30 \mathrm{~min}$ or until the Triton X-114 lower phase showed a 10 -fold increase from the initial surfactant volume). The upper aqueous phases were stored for posterior analysis, and one volume of isobutanol (Sigma, 33064) was added to each tube. After homogenization and centrifugation $(6,000 \times \mathrm{g}$; $15 \mathrm{~min} ; 22^{\circ} \mathrm{C}$ ), the upper isobutanol phase and the insoluble middle-phase were discarded. The aqueous lower phase 
(rK39-HFBI semi-purified extract) was submitted for analysis (Joensuu et al., 2010; Reuter et al., 2014, 2016).

\section{Protein Quantification, SDS-PAGE, and Western Blotting}

Total soluble proteins (TSP) of all extracts were quantified (Bradford, 1976) and analyzed using a 12\% SDS-PAGE (Laemmli, 1970). For the protein expression kinetics, $20 \mu \mathrm{g}$ of leaf extract of each time point were submitted to Western Blotting analysis using mouse antisera against $E$. coli expressed His-tagged rK39 (1:250 dilution) and the peroxidase-conjugated anti-Mouse IgG $(1: 5,000)$ (Invitrogen, G21040).

The same antisera were used to discard cross-reactivity against $N$. benthamiana and A. tumefaciens proteins. For this, $10 \mu \mathrm{g}$ of TSP from rK39-HFBI infiltrated plants were analyzed and compared to the same amount of TSP from control plants: p19-only infiltrated leaves and GFP-HFBI infiltrated leaves. Around $500 \mathrm{ng}$ of the His-tagged rK39 protein purified from E. coli were used as a positive control.

For western blottings using the sera of dogs naturally infected by $L$. infantum, the pooled sera were diluted (1:250) and incubated with the nitrocellulose membrane for $1 \mathrm{~h}$ at $37^{\circ} \mathrm{C}$. Peroxidase conjugated anti-Dog IgG (Sigma, SAB3700101) was used as the second antibody $(1: 5,000)$, and Clarity ${ }^{\mathrm{TM}}$ Western ECL Substrate (Bio-Rad, 1705060) was used for membrane development. For c-myc detection, a monoclonal anti-human c-myc antibody (Sigma, M4439) was used as the primary antibody $(1: 2,500)$, and the membrane was developed using 3,3'-Diaminobenzidine (Sigma, D8001) solution.

\section{rK39-HFBI PTA-ELISA for Canine Visceral Leishmaniasis Diagnosis}

The population of this study comprised the sera from 118 visceral leishmaniasis positive dogs (DPP positive followed by EIE-LVC positive tests), 20 false-positive sera (DPP positive followed by EIE-LVC negative tests), and 20 negative sera (DPP negative), according to the protocol adopted by the Brazilian government for the diagnosis of canine visceral leishmaniasis (de Carvalho et al., 2018).

The rK39-HFBI semi-purified extract was diluted into coating buffer $(0.1 \mathrm{M}$ sodium carbonate, $\mathrm{pH} 9,5)$ to the concentration of $1 \mu \mathrm{g} / \mathrm{ml}$. Then, $100 \mu \mathrm{l}$ of the diluted extract was used to coat each microplate well (Sigma, M9410). After overnight coating, the plates were washed with PBS-T [0.05\% Tween ${ }^{\circledR} 20$ (Sigma, P9416)], blocked for $1 \mathrm{~h}$ with $1 \%$ gelatin (Sigma, G6650) and then washed three times with PBS-T. The canine sera were individually diluted in PBS (1:160) and tested in duplicates. After incubating the sera for $1 \mathrm{~h}$ at $37^{\circ} \mathrm{C}$, another washing step was performed, and $100 \mu \mathrm{l}$ of peroxidase-conjugated anti-Dog IgG (Sigma, SAB3700101; 1:5,000) was added. After a final washing step, $100 \mu \mathrm{l}$ of TMB solution (Thermo, 34028) were added to each well, and the plates were incubated for $20 \mathrm{~min}$ in the dark. The reaction was stopped with $100 \mu \mathrm{l}$ of $2 \mathrm{M} \mathrm{H}_{2} \mathrm{SO}_{4}$ solution and the absorbance at $450 \mathrm{~nm}$ was read using a microplate reader (Synergy $^{\mathrm{TM}}$ 2, Biotek; Florindo et al., 2002). The same procedures were followed for the analysis of the rK39 purified protein.

\section{Statistical Analysis}

The ELISA's cut-off values and the sensitivity and the specificity of each recombinant antigen were estimated using the Receiver Operating Characteristic (ROC) curves generated by MedCalc ${ }^{\circledR}$ statistical software 17.2. The pairwise comparison of ROC curves was done according to DeLong et al. (1988). Statistical analysis was performed by one-way (ANOVA) using the KruskalWallis multiple comparison test. All the statistical analyses and graphs were generated by the GraphPad Prism 7 release 6.0.

\section{Ethical Statements}

All the experiments were conducted following the guidelines of the State University of Ceará Institutional Animal Care and Use Committee (protocols 3630450/2015 and 7255099/2017).

\section{RESULTS}

\section{rK39-HFBI Protein Analysis in Agroinfiltrated $\boldsymbol{N}$. benthamiana's Leaves}

To produce the rK39 antigen fused to a hydrophobin, we infiltrated the leaves of 6-8 weeks old $N$. benthamiana with an A. tumefaciens LBA4404 culture transformed with a binary plasmid containing the construct rK39-HFBI.

After infiltration, the best time for protein accumulation was empirically determined. For rK39-HFBI, the protein expression dynamics' evaluation required normalization by the leaf area instead of the fresh plant weight, since necrosis of the leaf tissue was initiated at 6 d.p.i. and progressed until the material was infeasible for analysis at 10 d.p.i. (data not shown). The necrotic process was compatible with the lower level of expression detected at 6 and 8 d.p.i., even when equal amounts of total soluble protein were loaded into each lane for western blotting analysis. The Western blotting analysis of the leaves' TSP evidenced a band of molecular weight close to $50 \mathrm{kDa}$, compatible with the $48.1 \mathrm{kDa}$ expected size for the K39 protein when expressed in the pCamGATE-ER-HFBI vector (Figure 2).

As a control for our assays and comparison of test performance, the rK39 protein was also produced and purified from E. coli culture. The use of a monoclonal antibody specific for the $\mathrm{His}_{6}$ tag of the rK39 antigen produced in E. coli enabled the detection of a single band of $37 \mathrm{kDa}$, equivalent to the size expected for the K39 protein of L. infantum when expressed in the pET-28a vector (Figure 3).

\section{Western Blotting Analysis of Total Soluble Proteins From rK39-HFBI Infiltrated Leaves Against the Sera From rK39 Immunized BALB/c Mice and Naturally Infected Dogs}

To assess whether host plant proteins would affect the specific recognition of the rK39-HFBI antigen, we did a Western blotting of the total soluble proteins from infiltrated and control leaves using $\mathrm{BALB} / \mathrm{c}$ mice's sera raised against the $\mathrm{rK} 39$ antigen produced in E. coli, as well as sera samples from dogs diagnosed with visceral leishmaniasis. 


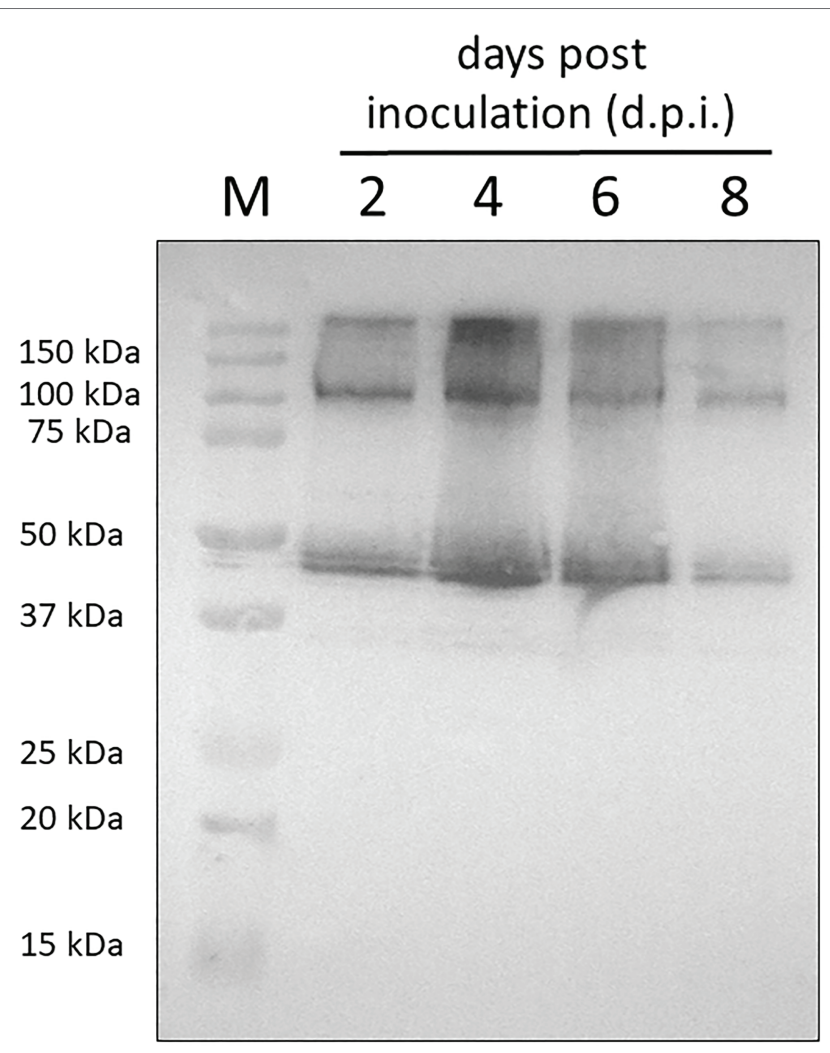

FIGURE 2 | Evaluation of rK39-HFB| expression in infiltrated leaves. Western blotting against $20 \mu \mathrm{g}$ of total soluble proteins (TSPs) from rK39-HFBI infiltrated leaves at 2-, 4-, 6-, and 8-days post infiltration (d.p.i.).
Western blotting with control plants was done to discard any antibody cross-reactivity against the host plant or the $A$. tumefaciens proteins (Figure 4A). As it can be seen, only bands from the rK39-HFBI plant extract and the prokaryotic K39 control were specifically detected. No reaction could be seen against equivalent amounts of control plant extracts (p19 infiltrated) or with plants agroinfiltrated with a hydrophobinfused control protein. Similar results were observed using the antisera from dogs naturally infected with $L$. infantum (Figure 4B).

\section{Aqueous Two-Phase System Purification of the rK39-HFBI Protein}

The addition of the surfactant Triton $\mathrm{X}-114^{\mathrm{TM}}$ to the plant crude extract allows the partitioning of the HFBI fused protein away from host proteins, yielding an upper aqueous phase and an rK39-HFBI semi-purified extract (Figure 5A). In this study, the use of three concentrations of surfactant $(2,4$, and $8 \%)$ resulted in different yields of rK39-HFBI in the semipurified extracts. It is noteworthy that the rK39-HFBI semipurified extract's final volume depends on the amount of surfactant used (Figure 5B). After phase separation, the Triton $\mathrm{X}-114$ phase displays a 10 -times increase in its initial volume. Thus, each of these phases' final volume normalized the SDS-PAGE and western blotting shown (Figures 5C).

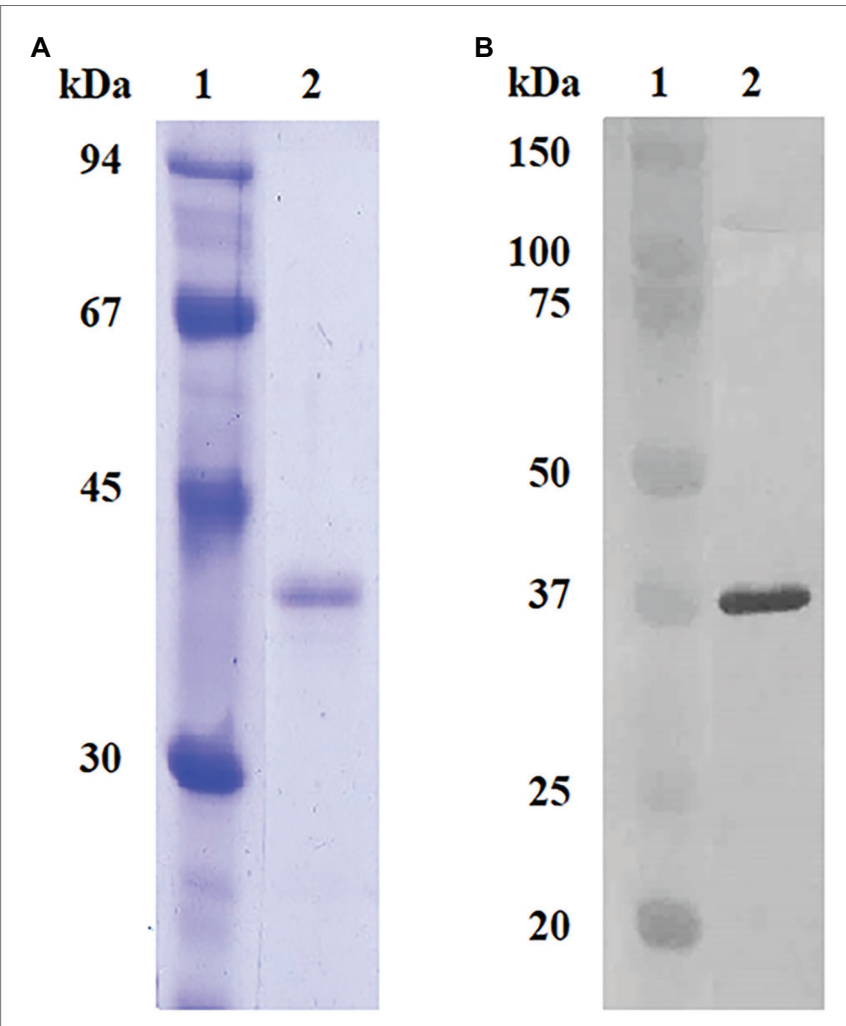

FIGURE 3 | SDS-PAGE and Western blotting of the recombinant proteins produced in E. coli and Nicotiana benthamiana. (A) Coomassie Brilliant Blue G-250 stained SDS-PAGE from the purified rK39 produced in E. coli.

(B) Western blotting of the purified rK39 produced in E. coli using an anti-His antibody.

As can be seen, at $2 \%$ of surfactant, a significant amount of the rK39-HFBI construct is lost at this upper aqueous phase; however, an increased surfactant concentration displaces the rK39-HFBI construct of this fraction toward the surfactant phase, as seen at 4 and $8 \%$ of Triton X-114 (Figure 5C). We chose to work with the intermediary concentration of $4 \%$, as it had a good balance between the final volume of rK39HFBI semi-purified fraction and the amount of surfactant required. When the p19 control plants and the rK39-HFBI infiltrated leaves are submitted to ATPS, only in the latter, it is possible to visualize a specific band at $48 \mathrm{kDa}$ (Figure 6), demonstrating the successful partitioning of the construct to the surfactant phase.

\section{Evaluation of rK39-HFBI Semi-Purified Fraction for Canine Visceral Leishmaniasis Diagnosis by Plate Trapped Antigen-ELISA}

To validate the rK39-HFBI construct for L. infantum infection diagnosis, we tested it against a panel of positive and negative sera for canine visceral leishmaniasis. The same samples were also tested against the rK39 produced in E. coli to compare the performance of both platforms, prokaryotic and eukaryotic, in the diagnosis of visceral leishmaniasis. The diagnostic performance of each recombinant antigen is summarized. 

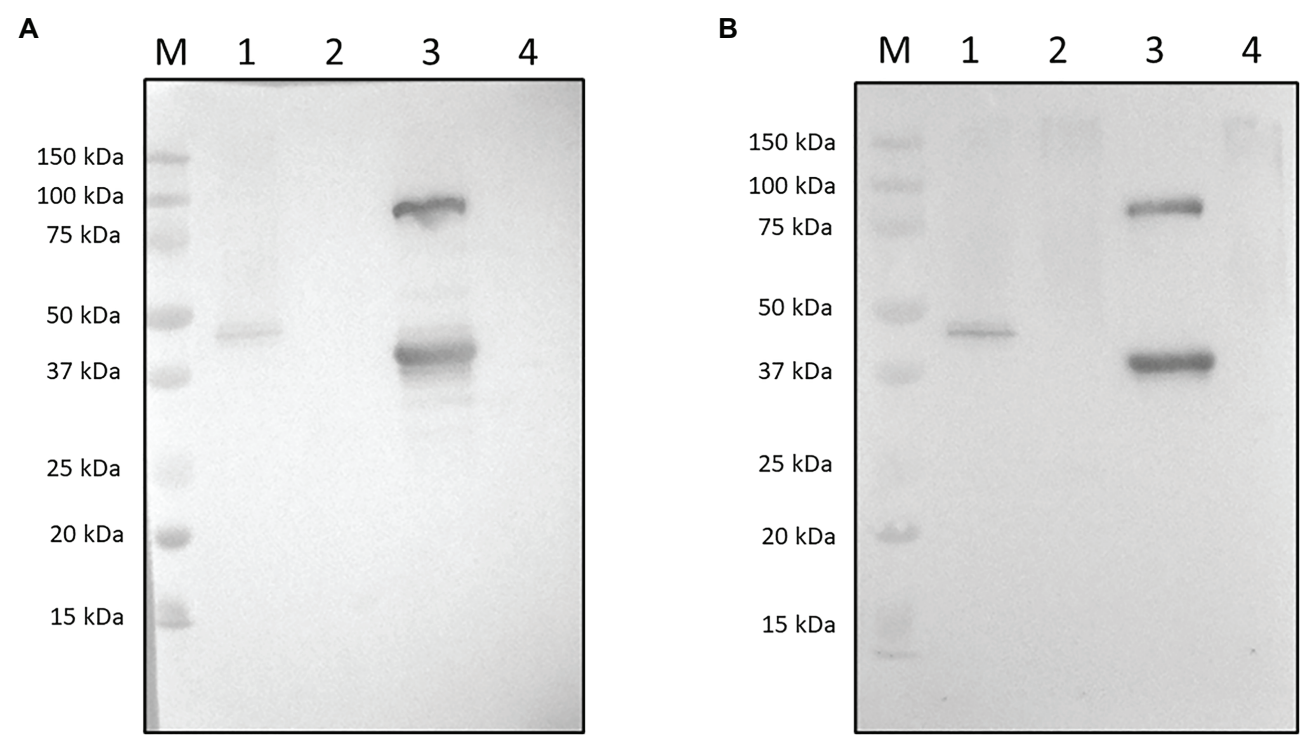

FIGURE 4 | Western Blotting of TSPs from rK39-HFBI infiltrated leaves. (A) Using mice antisera (1:250 dilution): (1) $10 \mu \mathrm{g}$ of total soluble proteins from rK39-HFBI infiltrated leaves; (2) About $10 \mu \mathrm{g}$ of total soluble proteins from p19-only infiltrated control plants; (3) Around 500 ng of His-tagged purified rK39; and (4) About $10 \mu \mathrm{g}$ of total soluble proteins from GFP-HFBI infiltrated control plants. (B) Against sera of $L$. infantum naturally infected dogs (1:250 dilution): (1) $10 \mu \mathrm{g}$ of total soluble proteins from rK39-HFBl infiltrated leaves; (2) Around $10 \mu \mathrm{g}$ of total soluble proteins from p19-only infiltrated control plants; (3) Around 500 ng of His-tagged purified rK39; and (4) About $10 \mu \mathrm{g}$ of total soluble proteins from GFP-HFBI infiltrated control plants.

Eleven samples from the DPP+/EIE+ group differed in our analyzes. Of these, two samples were negative only for $\mathrm{rK} 39$ (Figure 7A) and three samples for rK39-HFBI (Figure 7B). The other six samples were negative for both recombinant proteins. When the results from the rK39-HFBI and rK39 ELISA tests were compared for the DPP+/EIE- group (considered healthy animals by the Brazilian government protocol), we verified that one sample was positive in both of our tests, while another was positive only for the rK39.

Although the ROC curve analysis of the area under the curve (AUC) showed similar performance of rK39-HFBI $(\mathrm{AUC}=0.970)$ compared to $\mathrm{rK3} 3(\mathrm{AUC}=0.973)$, the data showed higher specificity for the rK39-HFBI semi-purified extract $(97.5 \%)$ rather than the purified prokaryotic antigen (95.0\%). Our results have shown, however, that the semi-purified rK39-HFBI test had a lower sensitivity (90.7\%) compared to its prokaryotic counterpart (93.2\%; Figure 8).

\section{DISCUSSION}

In this work, the K39 antigen from L. infantum was transiently expressed in plants. After subcloning the K39 gene into the expression vector, each newly produced batch took only 6 days from A. tumefaciens growth to the purification and coating of microplates with the antigen for visceral leishmaniasis diagnosis. The use of ATPS to reduce purification costs resulted in the development of a semipurified rK39-HFBI test, which had a performance equivalent to the purified protein produced in E. coli. Thus, it highlights the transient expression system's potential for the fast and straightforward production of antigens for diagnostic tests against visceral leishmaniasis, as well as other human and veterinary diseases.

The high expression of rK39-HFBI at 4 d.p.i. falls into the time range reported in the literature for the most significant accumulation of transiently expressed proteins (4-10 d.p.i.; Shamloul et al., 2014). The expression of this protein was accompanied by necrosis of the leaves starting at 6 days post infiltration. The hypersensitive response of the plant cells against the A. tumefaciens infection could be the primary mechanism responsible for the necrotic process (Leuzinger et al., 2013; Cana-Quijada et al., 2018). These results are not unusual since different kinds of recombinant proteins might exert toxic effects over the leaf cells when overexpressed. In a murine model of malaria, Webster et al. (2009) reported maximum yields of the recombinant Plasmodium yoelii merozoite surface protein 4/5 (PyMSP4/5) at 2-7 d.p.i. accompanied by necrotic spots in the infiltrated leaves of $N$. benthamiana, corroborating our findings. Diaz et al. (2020) also report progressive damage to the $N$. benthamiana's leaf tissue due to the A.tumefaciens mediated transient expression of a saposin-like protein from Trichomonas vaginalis (rTvSaplip12). These authors report that a lower concentration of agrobacteria reduced the severity of the symptoms in infiltrated leaves but also led to a lower expression of rTvSaplip12.

The findings that the sera from K39 immunized mice, or naturally infected dogs, only reacted with the rK39-HFBI crude extract, reinforce that host protein contaminating a plant expressed antigen extract would not interfere with its use for immunodiagnosis. As control plant extracts showed no reaction 


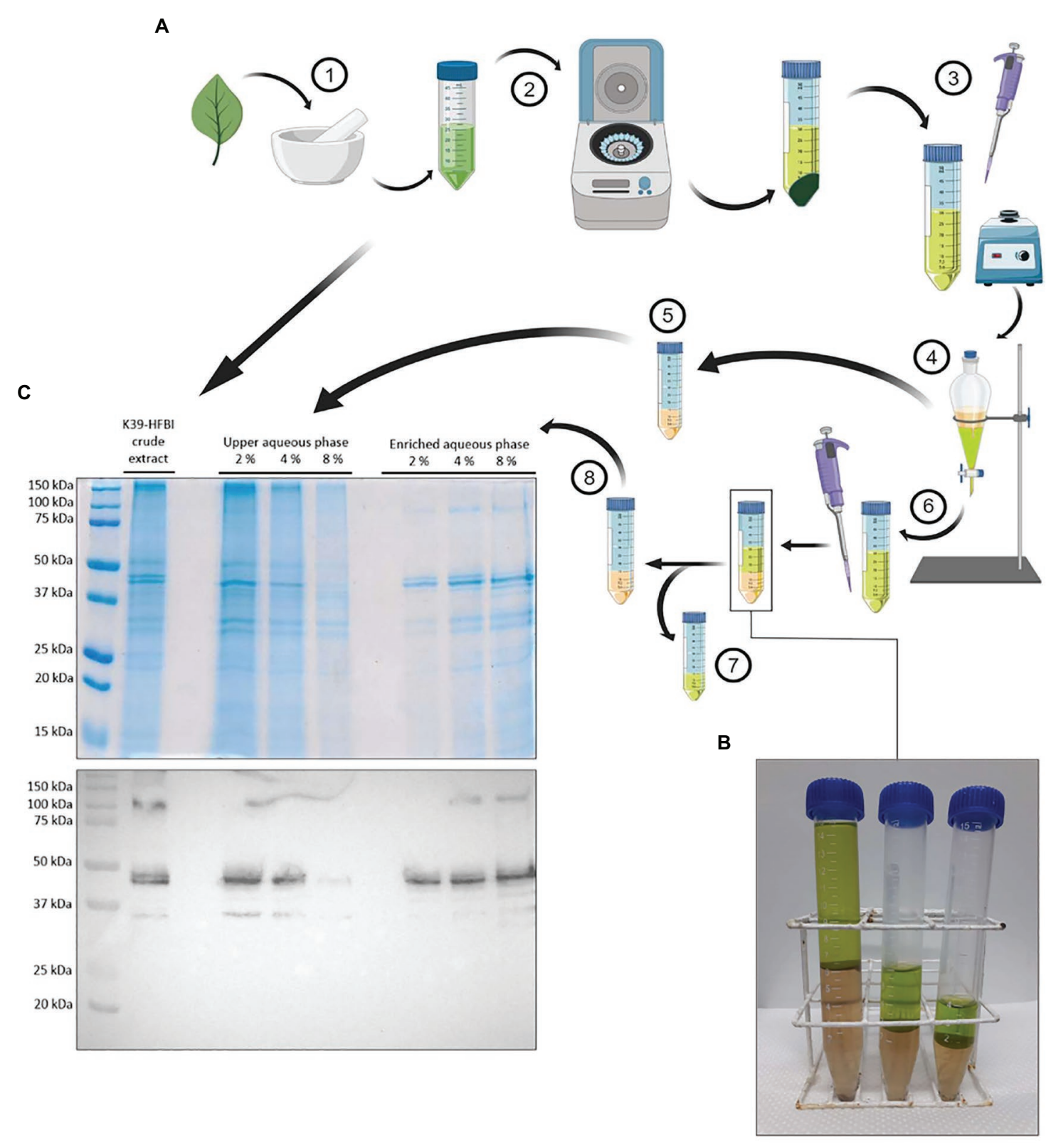

FIGURE 5 | Aqueous Two-Phase System (ATPS) separation for rK39-HFBI. (A) ATPS process: (1) rK39-HFBI infiltrated leaves are ground on liquid nitrogen and resuspended in 6 volumes of buffer; (2) rK39-HFBI crude extract is centrifuged for removal of cell debris; (3) The surfactant Triton X-14 is added (2, 4, or 8\%, v/v) to the supernatant and homogenized; (4) This mixture is incubated at $30^{\circ} \mathrm{C}$ for phase-separation; (5) The aqueous upper phase is reserved for posterior analysis; (6) Isobutanol is added to the lower surfactant phase, homogenized and centrifuged for a new phase separation; (7) The isobutanol upper phase is discarded; and (8) The lower aqueous rK39-HFBI semi-purified fraction is analyzed. (B) The final volume of rK39-HFBI semi-purified fraction (lower phase) is proportional to the amount of Triton X-114 used (8, 4, and $2 \%$ from left to right). (C) SDS-PAGE and Western Blotting of the ATPS resulting fractions. K39-HFBI crude extract: $10 \mu g$; ATPS fractions: volume loaded proportional to the final volume of each fraction (from left to right: upper aqueous phase (20, 10, and $5 \mu$ )), semi-purified fraction: $(5,10$, and $20 \mu l)$. Created with Biorender.

to infected dogs' antisera, it reassured the potential of transient plant expression as a reliable system for the production of antigens for immunodiagnosis without the need for intensive purification.

Plate Trapped Antigen-ELISA (PTA-ELISA) tests from plant extracts have already been demonstrated as a stable platform for low-cost detection of virus (Mowat and Dawson, 1987;
Nascimento et al., 2017). Thus, it could be used to expand access to visceral leishmaniasis diagnosis in low-income countries. Once the recombinant protein was transiently expressed, the plant extract could be easily used for coating microplates for serological diagnostic.

A significant concern toward PTA-ELISA is the stability of this type of test based on non-purified antigens. However, 


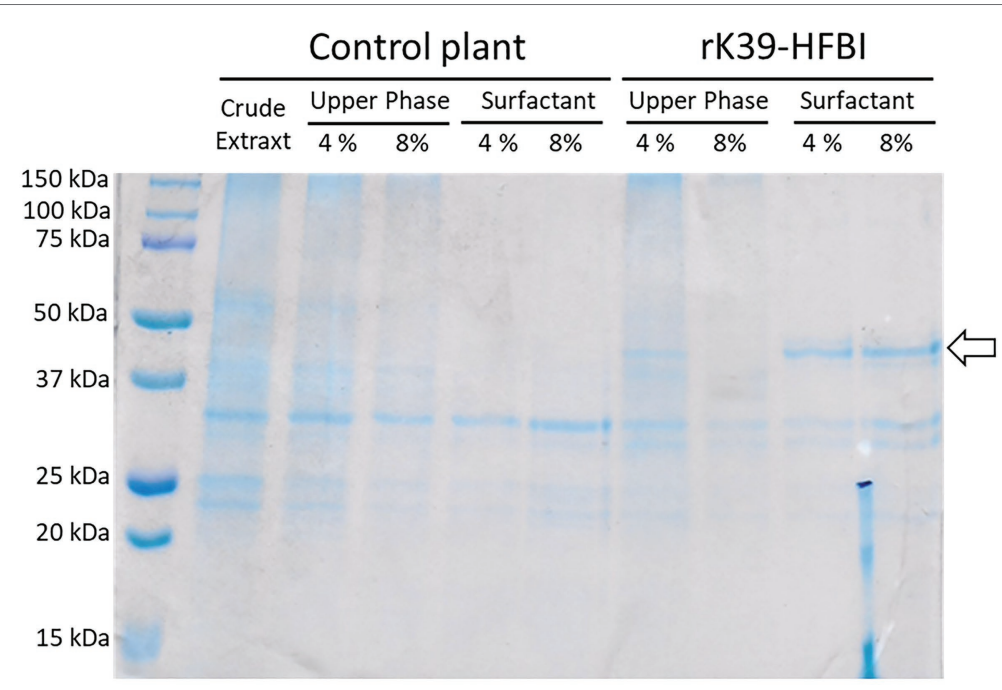

FIGURE 6 | SDS-PAGE of the ATPS resulting fractions from control plants and from rK39-HFBl infiltrated leaves. Control plant crude extract: 10 $\mu$ g. ATPS fractions: volume loaded proportional to the final volume of each fraction [upper aqueous phase: $4 \%(20 \mu \mathrm{l})$ and $8 \%(10 \mu \mathrm{l})$, semi-purified fraction: $4 \%(10 \mu \mathrm{l})$ and $8 \%(20 \mu \mathrm{l})$ ]. The arrow indicates the K39-HFBI construct $(\sim 48 \mathrm{kDa})$, absent in the control plants.

A

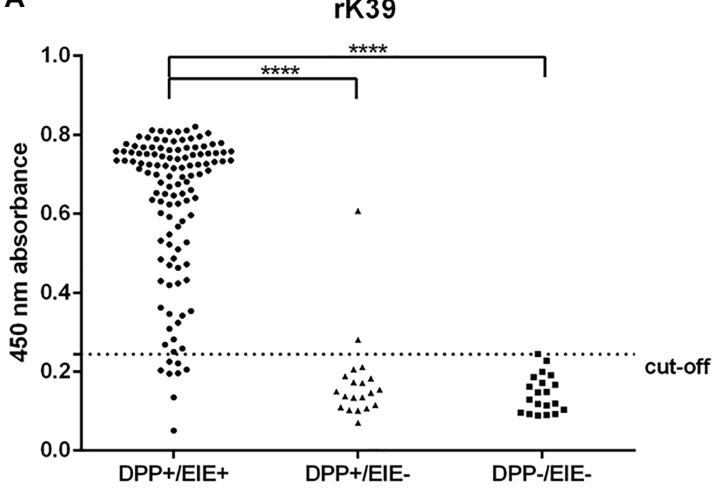

B

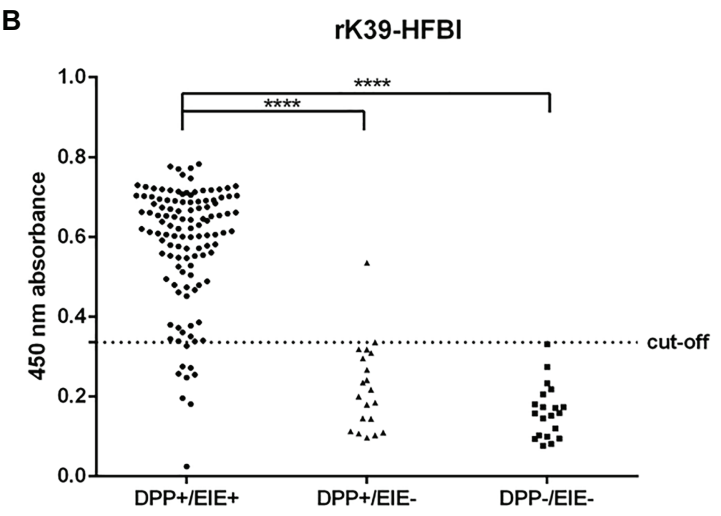

FIGURE 7 | ELISA with canine positive and negative sera for L. infantum infection according to the Brazilian government protocol. (A) Samples evaluated using plates coated with $100 \mathrm{ng} /$ well of rK39 purified protein. (B) Samples evaluated using plates coated with 100 ng/well of rK39-HFBI semi-purified extract. DPP+: Dual Path Platform positive for canine visceral leishmaniasis; DPP-: Dual Path Platform negative for canine visceral leishmaniasis; EIE+, Immunoenzymatic assay positive for canine visceral leishmaniasis; EIE-, Immunoenzymatic assay negative for canine visceral leishmaniasis. ANOVA followed by Kruskal-Wallis test, ${ }^{\star \star \star \star ~}<0.0001$ [(DPP-) vs. (DPP + /EIE+); (DPP + /EIE-) vs. (DPP + /EIE+)].

stability of up to 20 months at room temperature has been described for a PTA-ELISA for the detection of plant viruses (Nascimento et al., 2017). Another disadvantage of using total soluble proteins in a PTA-ELISA is that it can lead to a lower sensitivity as the recombinant protein is diluted into the host proteins pool (Garnsey and Cambra, 1993), and the plant compounds could interfere with the reaction.

Therefore, to attain a simple way to concentrate the L. infantum K39 protein from the plant crude extract, we fused this protein to the hydrophobin I gene from the fungus Trichoderma reesei. The hydrophobins are a class of proteins with tensioactive properties. Once exposed to hydrophobichydrophilic interfaces, the hydrophobin monomers undergo conformational changes and associate to form an amphipathic layer (Bayry et al., 2012; Berger and Sallada, 2019). By adding different amounts of the surfactant Triton $\mathrm{X}-114^{\mathrm{TM}}$ to the plant crude extract, we could concentrate the rK39-HFBI construct. This process, termed ATPS (Linder et al., 2004), allows the partitioning of the HFBI fused protein away from host proteins, yielding an upper aqueous phase and an rK39-HFBI semipurified extract.

Plant expression systems are particularly advantageous for the production of hydrophobin fused proteins. These fusion partners induce the accumulation of the heterologous protein expressed, increasing their yield and stability in protein bodies. Besides, the presence of few plant proteins with similar affinity to the surfactant results in a higher purity of the hydrophobin semi-purified extract when produced in a plant-based platform (Reuter et al., 2016). 


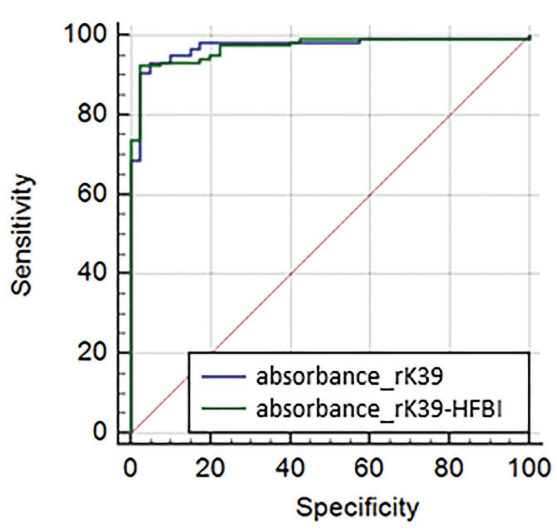

\begin{tabular}{|l|l|}
\hline Variable 1 & absorbance_rK39 \\
\hline Variable 2 & absorbance_rK39-HFBI \\
\hline Classification variable & DPP+EIE TEST \\
\hline Sample size & 158 \\
\hline Positive group a & $118(74.68 \%)$ \\
\hline Negative group b & $40(25.32 \%)$ \\
\hline
\end{tabular}

\begin{tabular}{|l|r|r|r|}
\hline Variable & AUC & SE & $95 \% \mathrm{Cl}^{\mathrm{b}}$ \\
\hline absorbance_rK39 & 0.973 & 0.0128 & 0.934 to 0.992 \\
\hline absorbance_rK39-HFBI & 0.970 & 0.0125 & 0.930 to 0.991 \\
\hline
\end{tabular}

PAIRWISE COMPARISON OF ROC CURVES

\begin{tabular}{|l|r|}
\hline absorbance_rK39 absorbance_rK39-HFBI \\
\hline Difference between areas & 0.00233 \\
\hline Standard Error ${ }^{\text {a }}$ & 0.00549 \\
\hline 95\% Confidence Interval & -0.00843 to 0.0131 \\
\hline z statistic & 0.425 \\
\hline Significance level & $\mathrm{P}=0.6712$ \\
\hline \multicolumn{2}{|c|}{${ }^{2}$ DeLong et al. (1988) }
\end{tabular}

SENSITIVITY AND SPECIFICITY OF THE TESTS

\begin{tabular}{|l|c|c|}
\hline & Sensitivity & Specificity \\
\hline rK39 & $93.2 \%$ & $95.0 \%$ \\
\hline rK39-HFBI & $90.7 \%$ & $97.5 \%$ \\
\hline
\end{tabular}

FIGURE 8 | Sensitivity, specificity, and pairwise comparison of Receiver Operating Characteristic (ROC) curves of rK39 and rK39-HFBI tests. The calculations considered positive and negative for visceral leishmaniasis samples from a sera panel tested according to the serological diagnostic protocol adopted by the Ministry of Health in Brazil.

Joensuu et al. (2010) were the first to report the biotechnological potential of hydrophobin fusions for the production and purification of recombinant proteins transiently expressed in plants. In their work, the fusion of HFBI to the c-terminus of GFP doubled its production over the unfused control (approximately 38 and $18 \%$ of total soluble proteins, respectively). Despite the necrotic process seen in our work, these authors report that the HFBI fusion was able to prevent the necrosis of the infiltrated $N$. benthamiana leaves and enabled the purification of GFP-HFBI at $91 \%$ purity, yielding up to $10 \mathrm{mg} / \mathrm{ml}$ of purified recombinant protein.

The rK39-HFBI semi-purified fraction allowed the development of a Plate Trapped Antigen-ELISA for canine visceral leishmaniasis diagnosis. However, since our data relies on a serological panel, its validation against a gold standard (parasitological test) or a $100 \%$ specific test (qPCR; Nunes et al., 2015; de Carvalho et al., 2018) still is required. Despite this, our test has shown a good concordance with the results from the official protocol adopted by the Brazilian government, and it shows that plant-produced rK39-HFBI could be used for the diagnosis of visceral leishmaniasis.

An increasing number of Leishmania recombinant antigens have been developed and evaluated for serodiagnosis (Farahmand and Nahrevanian, 2016; Salles et al., 2017; Kühne et al., 2019). The low sensitivity of the tests currently used is the major drawback for the serological diagnosis of visceral leishmaniasis (Teixeira et al., 2019). However, diagnostic tests based on recombinant proteins allow the use of multiple proteins (isolated or as chimeric proteins) as a strategy for improving the performance of the produced test (Travi et al., 2018). 
The expression of antigens in plants is a tool mainly used to produce antigens for vaccine development. In this context, the successful production of antigens from protozoa such as Trypanosoma cruzi, Plasmodium falciparum, and Toxoplasma gondii (the etiological agents of Chagas disease, malaria, and toxoplasmosis, respectively), have been described (Mamedov et al., 2019; Ramos-Vega et al., 2021). This platform's potential for the production of diagnostic antigens is still poorly explored (Schillberg et al., 2019), which led us to assess its features. This paper is the first work, to our knowledge, that used the plant transient expression system to produce a protozoan antigen to develop a diagnostic test.

The plant transient expression platform has shown great potential for producing and assessing new antigens for Neglected Tropical Diseases diagnosis even at a bench-scale. Since multiple proteins could be simultaneously produced (Chen et al., 2014) and tested against a panel of patient sera, this platform facilitates the discovery and validation of new biomarkers for disease diagnosis at low-resource research settings. Furthermore, the fusion of a hydrophobin partner to the produced antigen favors its immobilization into Point-of-Care devices (Zhao et al., 2007; Piscitelli et al., 2017; Zhang et al., 2018), for the development of diagnostic devices technically feasible, affordable, and adequate to different clinical settings (Karl et al., 2015), which also eliminates the need to remove the purification tag by additional steps (Islam et al., 2019).

This work aimed to evaluate the semi-purified rK39-HFBI diagnostic performance for the serological diagnosis of canine visceral leishmaniasis. The promising results found with the K39 antigen of L. infantum have opened the way for (ongoing) tests with other protozoan antigens and antigens from viral diseases like dengue and zika fever, and even COVID-19. Our group is completing a detailed cost-benefit analysis of this platform and also evaluating the test's stability over 1 year to establish its shelf life.

A detailed analysis of the production costs was not within the scope of this work, but our data reinforce that plant transient expression of antigens can be a competitive platform for developing diagnostic tests based on semi purified antigens. Based on our experiments' usual yields, we estimate that from $16 \mathrm{~g}$ of leaf tissue (approximately 4-5 N. benthamiana plants), we could obtain enough semi purified rK39-HFBI protein to coat 200 units of 96-well microplates and test at least 9,000 dogs. This level of performance can be further enhanced by optimizing the production process of the recombinant antigen (Grosse-Holz et al., 2018; Peyret et al., 2019; Sainsbury, 2020).

\section{REFERENCES}

Bayry, J., Aimanianda, V., Guijarro, J. I., Sunde, M., and Latgé, J.-P. (2012). Hydrophobins - unique fungal proteins. PLoS Pathog. 8:e1002700. doi: 10.1371/ journal.ppat. 1002700

Berger, B. W., and Sallada, N. D. (2019). Hydrophobins: multifunctional biosurfactants for interface engineering. J. Biol. Eng. 13, 1-8. doi: 10.1186/ s13036-018-0136-1

Bradford, M. M. (1976). A dye binding assay for protein. Anal. Biochem. 72, 248-254. doi: 10.1016/0003-2697(76)90527-3
Thus, we have demonstrated that the transient expression of the hydrophobin-fused K39 antigen allows its use to diagnose canine visceral leishmaniasis. The fusion to the HFBI partner allows the partial purification of the antigen at low-cost, and the contaminant host proteins present on this extract do not interfere with the specific diagnosis of the disease. The high yields at bench-scale also support the use of this platform to produce and validate new antigens for the diagnosis of other human and veterinary diseases.

\section{DATA AVAILABILITY STATEMENT}

The raw data supporting the conclusions of this article will be made available by the authors, without undue reservation.

\section{ETHICS STATEMENT}

The animal study was reviewed and approved by Ethics Committee on Animal Use, State University of Ceará, Fortaleza, Brazil.

\section{AUTHOR CONTRIBUTIONS}

BS, ES, ET, MT, and MG designed the experiments. BS and ES performed the experiments and wrote the manuscript. LA performed the mice immunizations and helped in the serology tests. $\mathrm{AB}$ and $\mathrm{LM}$ helped in the production and purification of the proteins. BS, ES, LA, AB, LM, ET, MT, and MG revised and edited the manuscript. All authors contributed to the article and approved the submitted version.

\section{FUNDING}

The authors acknowledge support from the Brazilian Northeast Biotechnology Network (Renorbio) and funding from the CAPES and FUNCAP agencies.

\section{ACKNOWLEDGMENTS}

The authors thank Dr. Rima Menassa and the Agriculture and Agri-Food Canada (AAFC) for kindly providing the expression vector used in this work. 
production of pharmaceutical proteins. Adv. Tech. Biol. Med. 1, 1-21. doi: 10.4172/atbm.1000103

de Carvalho, F. L. N., de Oliveira Riboldi, E., Bello, G. L., Ramos, R. R., Barcellos, R. B., Gehlen, M., et al. (2018). Canine visceral Leishmaniasis diagnosis: a comparative performance of serological and molecular tests in symptomatic and asymptomatic dogs. Epidemiol. Infect. 146, 571-576. doi: 10.1017/S0950268818000225

DeLong, E. R., DeLong, D. M., and Clarke-Pearson, D. L. (1988). Comparing the areas under two or more correlated receiver operating characteristic curves: a nonparametric approach. Biometrics 44, 837-845. doi: 10.2307/2531595

Diaz, N., Lico, C., Capodicasa, C., Baschieri, S., Dessì, D., Benvenuto, E., et al. (2020). Production and functional characterization of a recombinant predicted pore-forming protein (TVSAPLIP12) of Trichomonas Vaginalis in Nicotiana Benthamiana plants. Front. Cell. Infect. Microbiol. 10:581066. doi: 10.3389/ fcimb.2020.581066

Farahmand, M., and Nahrevanian, H. (2016). Application of recombinant proteins for Serodiagnosis of visceral Leishmaniasis in humans and dogs. Iran. Biomed. J. 20, 128-134. doi: 10.7508/ibj.2016.03.001

Faria, A. R., and de Andrade, H. M. (2012). Diagnóstico Da Leishmaniose Visceral Canina: Grandes Avanços Tecnológicos e Baixa Aplicação Prática. Revista Pan-Amazônica de Saúde. 3, 47-57. doi: 10.5123/S2176-62232012 000200007

Florindo, M. I., De Aragão, M. E. F., Da Silva, A. C. M., Otoch, M. L., Fernandes De Melo, D., Lima, J. A. A., et al. (2002). Immune response induced in mice by oral immunization with cowpea severe mosaic virus. Braz. J. Med. Biol. Res. 35, 827-835. doi: 10.1590/S0100-879X2002000700011

Garnsey, S. M., and Cambra, M. (1993). "Enzyme-linked Immunosorbent assay (ELISA)," in Graft-Transmissible Diseases of Grapevines Handbook for Detection and Diagnosis. ed. G. P. Martelli (Rome: Food and Agriculture Organization of the United Nations). Available at: http://www.fao.org/3/t0675e/T0675E0f. htm\#Enzyme-linked immunosorbent assay (ELISA) (Accessed April 06, 2021).

Goto, Y., Carter, D., Guderian, J., Inoue, N., Kawazu, S. I., and Reed, S. G. (2010). Upregulated expression of B-cell antigen family tandem repeat proteins by Leishmania amastigotes. Infect. Immun. 78, 2138-2145. doi: 10.1128/ IAI.01102-09

Grosse-Holz, F., Madeira, L., Zahid, M. A., Songer, M., Kourelis, J., Fesenko, M., et al. (2018). Three unrelated protease inhibitors enhance accumulation of pharmaceutical recombinant proteins in Nicotiana benthamiana. Plant Biotechnol. J. 16, 1797-1810. doi: 10.1111/pbi.12916

Islam, M. R., Kwak, J. W., Lee, J. S., Hong, S. W., Khan, M. R. I., Lee, Y., et al. (2019). Cost-effective production of tag-less recombinant protein in Nicotiana benthamiana. Plant Biotechnol. J. 17, 1094-1105. doi: 10.1111/ pbi. 13040

Joensuu, J. J., Conley, A. J., Lienemann, M., Brandle, J. E., Linder, M. B., and Menassa, R. (2010). Hydrophobin fusions for high-level transient protein expression and purification in Nicotiana benthamiana. Plant Physiol. 152, 622-633. doi: 10.1104/pp.109.149021

Kapila, J., De Rycke, R., Van Montagu, M., and Angenon, G. (1997). An agrobacterium-mediated transient gene expression system for intact leaves. Plant Sci. 122, 101-108. doi: 10.1016/S0168-9452(96)04541-4

Karl, S., Jones, M. K., Gutiérrez, L., Moore, B., Kattenberg, E., and Lacerda, M. (2015). Challenges for diagnosis of malaria and neglected tropical diseases in elimination settings. Biomed. Res. Int. 2015:270756. doi: 10.1155/2015/270756

Kühne, V., Rezaei, Z., Pitzinger, P., and Büscher, P. (2019). Systematic review on antigens for Serodiagnosis of visceral Leishmaniasis, with a focus on East Africa. PLoS Negl. Trop. Dis. 13:e0007658. doi: 10.1371/journal.pntd.0007658

Laemmli, U. K. (1970). Cleavage of structural proteins during the assembly of the head of bacteriophage T4. Nature 227, 680-685. doi: 10.1038/227680a0

Leuzinger, K., Dent, M., Hurtado, J., Stahnke, J., Lai, H., Zhou, X., et al. (2013). Efficient agroinfiltration of plants for high-level transient expression of recombinant proteins. J. Vis. Exp. 23:50521. doi: 10.3791/50521

Linder, M. B., Qiao, M., Laumen, F., Selber, K., Hyytiä, T., Nakari-Setälä, T., et al. (2004). Efficient purification of recombinant proteins using Hydrophobins as tags in surfactant-based two-phase systems. Biochemistry 43, 11873-11882. doi: 10.1021/bi0488202

Mamedov, T., Cicek, K., Miura, K., Gulec, B., Akinci, E., Mammadova, G., et al. (2019). A plant-produced in vivo Deglycosylated full-length Pfs48/45 as a transmission-blocking vaccine candidate against malaria. Sci. Rep. 9:9868. doi: $10.1038 / \mathrm{s} 41598-019-46375-6$
Marcondes, M., and Day, M. J. (2019). Current status and Management of Canine Leishmaniasis in Latin America. Res. Vet. Sci. 123, 261-272. doi: 10.1016/j.rvsc.2019.01.022

Marques, L. É. C., Silva, B. B., Dutra, R. F., Tramontina, E. O. P., Florean, R. M., and Guedes, M. I. F. (2020). Transient expression of dengue virus NS1 antigen in Nicotiana Benthamiana for use as a diagnostic antigen. Front. Plant Sci. 10:1674. doi: 10.3389/fpls.2019.01674

Mello, M. V. C., de Aragão, M. E. F., Torres-Franklin, M. L. P., de Oliviera Neto, J. M., and Guedes, M. I. F. (2011). Purification of infectious Myonecrosis virus (IMNV) in species of marine shrimp Litopenaeus vannamei in the state of Ceará. J. Virol. Methods 177, 10-14. doi: 10.1016/j. jviromet.2011.05.032

Mowat, W. P., and Dawson, S. (1987). Detection and identification of plant viruses by ELISA using crude sap extracts and unfractionated antisera. J. Virol. Methods 15, 233-247. doi: 10.1016/0166-0934(87)90101-7

Nascimento, A. K. Q., Lima, J. A. A., and da Silva Barbosa, G. (2017). A simple kit of plate-trapped antigen enzyme-linked immunosorbent assay for identification of plant viruses. Rev. Ciênc. Agron. 48, 216-220. doi: 10.5935/1806-6690.20170025

Nunes, C. M., de Lima, V. M. F., de Melo, G. D., de Paula, H. B., Pereira, M. E. G., de Melo Trinconi Tronco, C., et al. (2015). Serological, parasitological and molecular tests for canine visceral leishmaniosis diagnosis in a longitudinal study. Rev. Bras. Parasitol. Vet. 24, 402-409. doi: 10.1590/S1984-29612015073

Pereira, E. O., Kolotilin, I., Conley, A. J., and Menassa, R. (2014). Production and characterization of in planta transiently produced polygalacturanase from Aspergillus niger and its fusions with hydrophobin or ELP tags. BMC Biotechnol. 14:59. doi: 10.1186/1472-6750-14-59

Peyret, H., Brown, J. K. M., and Lomonossoff, G. P. (2019). Improving plant transient expression through the rational design of synthetic 5' and 3'untranslated regions. Plant Methods 15:108. doi: 10.1186/s13007-019-0494-9

Piscitelli, A., Pennacchio, A., Longobardi, S., Velotta, R., and Giardina, P. (2017). Vmh2 hydrophobin as a tool for the development of 'self-immobilizing' enzymes for biosensing. Biotechnol. Bioeng. 114, 46-52. doi: 10.1002/bit.26049

Ramos-Vega, A., Monreal-Escalante, E., Dumonteil, E., Bañuelos-Hernández, B. and Angulo, C. (2021). Plant-made vaccines against parasites: bioinspired perspectives to fight against Chagas disease. Expert Rev. Vaccines 5, 1-16. doi: $10.1080 / 14760584.2021 .1893170$

Reuter, L. J., Bailey, M. J., Joensuu, J. J., and Ritala, A. (2014). Scale-up of Hydrophobin-assisted recombinant protein production in tobacco BY-2 suspension cells. Plant Biotechnol. J. 12, 402-410. doi: 10.1111/pbi.12147

Reuter, L., Ritala, A., Linder, M., and Joensuu, J. (2016). Novel hydrophobin fusion tags for plant-produced fusion proteins. PLoS One 11:e0164032. doi: 10.1371/journal.pone.0164032

Robichon, C., Luo, J., Causey, T. B., Benner, J. S., and Samuelson, J. C. (2011). Engineering Escherichia coli BL21(DE3) derivative strains to minimize E. coli protein contamination after purification by immobilized metal affinity chromatography. Appl. Environ. Microbiol. 77, 4634-4646. doi: 10.1128/ AEM.00119-11

Rodrigues, M. H. C., Rodrigues, K. M., Oliveira, T. R., Cômodo, A. N., Rodrigues, M. M., Kocken, C. H. M., et al. (2005). Antibody response of naturally infected individuals to recombinant Plasmodium vivax apical membrane Antigen-1. Int. J. Parasitol. 35, 185-192. doi: 10.1016/j.ijpara.2004.11.003

Ruiz-Postigo, J. A., Grout, L., and Jain, S. (2020). Global Leishmaniasis surveillance, 2017-2018, and first report on 5 additional indicators. Wkly Epidemiol. Rec. 95, 265-280.

Saberianfar, R., and Menassa, R. (2017). Protein bodies: how the ER deals with high accumulation of recombinant proteins. Plant Biotechnol. J. 15, 671-673. doi: $10.1111 /$ pbi. 12730

Sainsbury, F. (2020). Innovation in plant-based transient protein expression for infectious disease prevention and preparedness. Curr. Opin. Biotechnol. 61, 110-115. doi: 10.1016/j.copbio.2019.11.002

Salles, B. C. S., Costa, L. E., Alves, P. T., Dias, A. C. S., Vaz, E. R., Menezes-Souza, D., et al. (2017). Leishmania Infantum Mimotopes and a phage-ELISA assay as tools for a sensitive and specific Serodiagnosis of human visceral Leishmaniasis. Diagn. Microbiol. Infect. Dis. 87, 219-225. doi: 10.1016/j. diagmicrobio.2016.11.012

Schillberg, S., Raven, N., Spiegel, H., Rasche, S., and Buntru, M. (2019). Critical analysis of the commercial potential of plants for the production of recombinant proteins. Front. Plant Sci. 10:720. doi: 10.3389/fpls.2019.00720 
Shamloul, M., Trusa, J., Mett, V., and Yusibov, V. (2014). Optimization and utilization of agrobacterium-mediated transient protein production in nicotiana. J. Vis. Exp. 86, 1-13. doi: 10.3791/51204

Teixeira, A. I. P., Silva, D. M., Vital, T., Nitz, N., de Carvalho, B. C., Hecht, M., et al. (2019). Improving the reference standard for the diagnosis of canine visceral Leishmaniasis: a challenge for current and future tests. Mem. Inst. Oswaldo Cruz 114:e180452. doi: 10.1590/0074-02760180452

Travi, B. L., Cordeiro-da-Silva, A., Dantas-Torres, F., and Miró, G. (2018). Canine visceral Leishmaniasis: diagnosis and management of the reservoir living among us. PLoS Negl. Trop. Dis. 12:e0006082. doi: 10.1371/journal. pntd.0006082

Tripathi, N. K. (2016). Production and purification of recombinant proteins from Escherichia coli. ChemBioEng Rev. 3, 116-133. doi: 10.1002/cben.201600002

Verhey, K. J., Kaul, N., and Soppina, V. (2011). Kinesin assembly and movement in cells. Annu. Rev. Biophys. 40, 267-288. doi: 10.1146/annurev-biophys042910-155310

Webster, D. E., Wang, L., Mulcair, M., Ma, C., Santi, L., Mason, H. S., et al. (2009). Production and characterization of an orally immunogenic plasmodium antigen in plants using a virus-based expression system. Plant Biotechnol. J. 7, 846-855. doi: 10.1111/j.1467-7652.2009.00447.x

WHO-PAHO (2018). LEISHMANIASES Leishmaniases: Epidemiological Report of the Americas, Report Laishmaniases 1: 1-4.
World Health Organization (2018). Global Leishmaniasis surveillance update, 1998-2016. Wkly Epidemiol. Rec. 93, 521-540.

Zhang, B., Gao, W., Piao, J., Xiao, Y., and Wang, B. (2018). Effective bioactivity retention of low-concentration antibodies on HFBI-modified fluorescence ICTS for sensitive and rapid detection of PSA. ACS Appl. Mater. Interfaces 10, 14549-14558. doi: 10.1021/acsami.8b02945

Zhao, Z.-x., Qiao, M.-q., Yin, F., Shao, B., Wu, B.-y., Wang, Y.-y., et al. (2007). Amperometric glucose biosensor based on self-assembly hydrophobin with high efficiency of enzyme utilization. Biosens. Bioelectron. 22, 3021-3027. doi: $10.1016 /$ j.bios.2007.01.007

Conflict of Interest: The authors declare that the research was conducted in the absence of any commercial or financial relationships that could be construed as a potential conflict of interest.

Copyright (c) 2021 Silva, Santos, Araújo, Bezerra, Marques, Tramontina Florean, van Tilburg and Guedes. This is an open-access article distributed under the terms of the Creative Commons Attribution License (CC BY). The use, distribution or reproduction in other forums is permitted, provided the original author(s) and the copyright owner(s) are credited and that the original publication in this journal is cited, in accordance with accepted academic practice. No use, distribution or reproduction is permitted which does not comply with these terms. 